\title{
Lipocalin-2, glucose metabolism and chronic low- grade systemic inflammation in Chinese people
}

\author{
Ying Huang ${ }^{1}$, Zhen Yang ${ }^{2 *}$, Zi Ye ${ }^{1}$, Qin Li ${ }^{1}$, Jie Wen ${ }^{1}$, Xiaoming Tao ${ }^{1}$, Lili Chen ${ }^{1}$, Min He ${ }^{1}$, Xuanchun Wang ${ }^{1}$, \\ Bin Lu', Zhaoyun Zhang ${ }^{1}$, Weiwei Zhang ${ }^{3}$, Shen $\mathrm{Qu}^{2}$ and Renming $\mathrm{Hu}^{1 *}$
}

\begin{abstract}
Background: Lipocalin-2 is a novel adipokine with connection to insulin resistance. In this study, we aimed to investigate the association of serum lipocalin-2 with glucose metabolism and other metabolic phenotype in a large-scale Chinese population.
\end{abstract}

Methods: We evaluated serum lipocalin-2 in a cross-sectional sample of 2519 Chinese aged from 50 to 82 year in a Shanghai downtown district by ELISA. Glucose, insulin, lipid profile, inflammatory markers, and adipokines were also measured.

Results: Serum lipocalin-2 was significantly higher in subjects with isolated impaired fasting glucose, isolated impaired glucose tolerance, combined impaired fasting glucose/impaired glucose tolerance and newly-diagnosed type 2 diabetes than in those with normal glucose regulation. Lipocalin-2 elevation was clearly associated with a higher risk for impaired glucose regulation (OR 1.30 for each $10 \mathrm{ng} / \mathrm{ml}$ increase in serum lipocalin-2, 95\% Cl 1.23$1.62, p=0.009$ ) after adjustment of age, gender, smoking, alcohol drinking, family history of diabetes, serum CRP, serum adiponectin, serum CXCL5, HOMA-IR, BMI, and waist/hip ratio. The OR for participants with impaired glucose regulation and type 2 diabetes was 1.31 (95\% Cl 1.21-1.69, $p<0.001$ ).

Conclusions: Our findings suggest that elevated serum lipocalin-2 is closely and independently associated with impaired glucose regulation and type 2 diabetes.

Keywords: Lipocalin-2, Impaired glucose regulation, Type 2 diabetes, Insulin resistance

\section{Background}

Obesity is a major risk factor for insulin resistance. It is well known that adipocytes could secrete a variety of biologically adipokines, which are thought to contribute to the development of insulin resistance and cardiovascular disease [1-3]. Lipocalin-2, a recently identified adipokine with high levels of expression and secretion in the white adipose tissue, seems to affect glucose metabolism and insulin sensitivity.

Lipocalin-2, also known as neutrophil gelatinase-associated lipocalin, neu-related lipocalin, siderocalin, uterocalin, and 24p3, belongs to the lipocalin super family. It shows high affinity to several small hydrophobic ligands

\footnotetext{
* Correspondence: yangzhen1020@hotmail.com; renminghu@fudan.edu.cn 'Institute of Endocrinology and Diabetology, Huashan hospital, Shanghai Medical College, Fudan University, Shanghai, China

${ }^{2}$ Department of Endocrinology, Shanghai tenth people's hospital, School of medicine, Tongji University, Shanghai, China

Full list of author information is available at the end of the article
}

such as retinoids, fatty acids, pheromones, steroids and iron [4-6]. Lipocalin-2 was found expressed in kidney, brain, lung, liver, neutrophils, adipocytes as well as macrophages and was involved in varieties of biological functions such as apoptosis, tumorigenesis and innate immunity [7-9].

Recent studies in animal models showed that lipocalin-2 also plays an important role in systemic insulin sensitivity and glucose homeostasis [10,11]. Lipocalin-2 suppression could attenuate aging and obesity-induced insulin resistance [12]. In human studies, it was reported that lipocalin-2 levels were elevated in both circulation and adipose tissue of obese people. Moreover, circulating lipocalin-2 concentration was positively correlated with insulin resistance index and inflammatory markers $[11,13]$. Furthermore, elevated serum lipocalin-2 levels were also observed among diabetic patients, and this increase could be reversed by the insulin-sensitizing drug rosiglitazone [11].

\section{Biomed Central}


However, evidence from large-scale populations about the relationship between lipocalin-2 and glucose metabolism, insulin resistance and chronic low-grade systemic inflammation is scarce.

To better evaluate the role of lipocalin- 2 in glucose metabolism, insulin resistance and chronic Low-grade systemic inflammation, we explored the association of serum lipocalin-2 levels with chronic inflammatory marker, insulin resistance and glucose metabolism states in a largescale Chinese population. We examined lipocalin-2 distribution in 2519 middle-aged and older Chinese subjects in a cross-sectional study and explored the association of serum lipocalin-2 levels with glucose metabolism as well as other metabolic parameters.

\section{Methods}

\section{Study population}

The design and recruitment of the population-based cross-sectional study has been described in detail elsewhere [14]. In 2007 China launched a national incidence trends of metabolic syndrome study. The data presented in this article are partially based on subsamples from Shanghai in eastern China (total 2598 subjects). All studied individuals came from the Simenerlu community of the Jingan District and the Jiangninglu community of the Putuo District in Shanghai, China. A multistage stratified cluster sampling method was used to select subjects from these two communities. Only one participant (> 50 year) was randomly selected from each household. In these 2598 subjects, 79 participants have previously diagnosed type 2 diabetes, all the others received the oral glucose tolerance test and 392 are newly diagnosed type 2 diabetes. In our study, all studied individuals were of southern Han Chinese ancestry and were residing in the metropolitan area of Shanghai aged 50-82 years. Briefly, a total of 2598 eligible participants (1106 men and 1492 women) were recruited. After excluding those who had previously diagnosed as type 2 diabetes and treated $(n=79), 2,519$ individuals were eligible for the present analysis. Written consent was obtained from all the participants. The study was approved by the institutional review broad of Huashan Hospital.

\section{Data collection}

A standardized questionnaire was used by trained physicians to collect information such as age, sex, smoking (yes/no), alcohol drinking (yes/no), and self-reported diabetes, hypertension, dyslipidemia. According to participants' responses to the corresponding questions, family history of diabetes was classified as yes or no.

All subjects were assessed after overnight fasting for at least $10 \mathrm{~h}$. The details of anthropometric measurements including height, weight, waist circumference, hip circumference and blood pressure were carried by trained physicians. BMI was calculated as weight in kilograms divided by the square of height in meters and categorized as normal weight $\left(<24.0 \mathrm{~kg} / \mathrm{m}^{2}\right)$, or overweight $\left(24-28 \mathrm{~kg} / \mathrm{m}^{2}\right)$, or obesity $\left(\geq 28.0 \mathrm{~kg} / \mathrm{m}^{2}\right)$, according to the criteria for Chinese individuals [15].

\section{Laboratory measurements}

Peripheral venous blood samples were collected. The fasting glucose, glucose $2 \mathrm{~h}$ after oral glucose tolerance test, total cholesterol, triglycerides, LDL-cholesterol and HDL-cholesterol were measured on an automatic analyzer (Hitachi 7080). Fasting insulin was determined by radioimmunoassay (Linco Research, St. Charles, MO). Insulin resistance was estimated using homeostasis model assessment index-insulin resistance (HOMA-IR).

Type 2 diabetes and prediabetes were defined by 2005 ADA criteria [16]. A fasting glucose level lower than $5.6 \mathrm{mmol} / \mathrm{l}$ and a $2 \mathrm{~h}$ OGTT plasma glucose level below $7.8 \mathrm{mmol} / \mathrm{l}$ were defined as normal glucose regulation (NGR). Impaired fasting glucose (IFG) and impaired glucose tolerance (IGT) were defined as fasting glucose 5.6 to $6.9 \mathrm{mmol} / \mathrm{l}$ and $2 \mathrm{~h}$ OGTT plasma glucose 7.8 to $11.0 \mathrm{mmol} / \mathrm{l}$ respectively. Of 2519 participants, $392 \mathrm{had}$ type 2 diabetes (screen-detected and treatment-naive), 335 had isolated-IFG (all screen-detected and treatmentnaive), 353 had isolated-IGT (all screen-detected and treatment-naive), 296 had IFG + IGT (all screen-detected and treatment-naive) and 1143 had NGR.

\section{Measurements of serum CRP, adiponectin, CXCL5 and lipocalin-2}

The serum CRP, adiponectin, CXCL5 and lipocalin-2 were determined in duplicate by ELISA with Duoset kit (DY1707, DY1065, DY254 and DY1757, R\&D Systems) as recommended by the manufacturer. The ELISA system had an intraassay coefficient of variation of 3.1-9.5\% and an interassay coefficient of variation of $4.3-10.7 \%$, respectively.

\section{Statistical analysis}

Normally distributed data were expressed as means \pm SD, whereas variables with a skewed distribution were reported as median (interquartile range) and log transformed to approximate normality before analysis. Categorical variables were represented by frequency and percentage. Univariate and multivariable stepwise regression analysis were used to investigate the association of serum lipocalin-2 with clinical and biochemical characteristics. The stepwise regression procedure was used to obtain determinants of serum lipocalin-2, potential confounding variables including age, gender, smoking, alcohol drinking, family history of diabetes, serum CRP, serum adiponectin, serum CXCL5, HOMA-IR, BMI, waist circumference, and waist/hip ratio were controlled 
in the regression models. To study the association of impaired glucose regulation (IGR) with lipocalin-2, we defined subjects with normal glucose regulation as $0(\mathrm{n}=$ $1143)$, and impaired glucose regulation as $1(\mathrm{n}=984)$, and excluded type 2 diabetic patients from logistic regression analysis. For the association of combined impaired glucose regulation and type 2 diabetes with lipocalin-2, we defined subjects with normal glucose regulation as $0(\mathrm{n}=1143)$ and combined impaired glucose regulation and type 2 diabetes as $1(n=1376)$ in the logistic regression analyses. Homogeneity of groups was determined when the means showed significant differences. Means of these groups were compared by the Student-Newman-Keuls method. All statistical analysis was performed with the SPSS Statistical Package (version 13.0; SPSS Inc., Chicago, IL). A p value of less than 0.05 was considered to be statistically significant.

\section{Results}

\section{General characteristics of the study participants}

Our study involved 1143 subjects with NGR and 392 with newly diagnosed type 2 diabetes (Table 1). Among those with impaired glucose regulation, 335 had isolated IFG, 353 had isolated IGT, and 296 had IFG + IGT. There was no significant difference in sex distribution, alcohol drinking and serum LDL-c levels between these groups. The NGR and diabetes groups had the most favorable and unfavorable metabolic profiles, respectively. There was no significant difference in waist circumference, waist/hip ratio, and serum triacylglycerol levels between groups with isolated IFG, isolated IGT and IFG + IGT.

\section{Determinants of serum lipocalin-2 concentrations}

Body mass index, waist circumference, $\log _{10}$ fasting serum insulin, $\log _{10}$ HOMA-IR, total cholesterol, HDL-cholesterol and serum CXCL5 levels were independent determinants for serum lipocalin-2 concentrations in the stepwise linear regression analysis (Table 2). In univariate analysis, serum lipocalin-2 levels were closely associated with serum $C$-reactive protein $(r=0.131, p<0.001)$. However, serum C-reactive protein was not an independent determinant for serum lipocalin-2 $(p>0.05)$.

\section{Lipocalin-2 distribution in different glucose metabolism status}

Serum lipocalin-2 levels were significantly associated with fasting plasma glucose $(\mathrm{r}=0.107, p<0.001)$ and $2 \mathrm{~h}$ OGTT plasma glucose $(\mathrm{r}=0.066, p=0.009)$ in total population. Serum lipocalin-2 concentrations were significantly higher in subjects with isolated IFG, isolated IGT, IFG + IGT, and newly diagnosed type 2 diabetes compared with those of subjects with NGR $(83.5,92.4,83.1,89.2 \mathrm{ng} / \mathrm{ml}$ vs $69.2 \mathrm{ng} / \mathrm{ml}$, respectively, all $p<0.01$ ) after adjustment for age, gender, BMI, and family history of diabetes. There was no statistical difference between the four groups with glucose metabolism dysregulation (all $p>0.05$, Figure 1).

Remarkably, as presented in Table 3, elevated lipocalin-2 was associated with increased risk of hyperglycemia. Elevated serum lipocalin indicated high risk for impaired glucose regulation (OR 1.30, 95\% CI 1.23-1.62, $p=0.009$ ) after adjustment for age, gender, smoking, alcohol drinking, family history of diabetes, serum CRP, serum adiponectin, serum CXCL5, HOMA-IR, BMI, waist/hip ratio, serum triacylglycerol, total cholesterol, HDL-cholesterol and LDL-cholesterol. The OR for subjects with impaired glucose regulation and type 2 diabetes was 1.31 (95\% CI $1.21-1.69, p<0.001)$.

\section{Discussion}

In this study, we found a strong correlation between serum lipocalin-2 levels and impaired glucose regulation as well as type 2 diabetes in a middle-aged and elderly Chinese population. Moreover, this association is independent of potential confounders.

Lipocalin-2 has been reported to be elevated in certain metabolic disorders, including obesity, polycystic ovary syndrome and type 2 diabetes [11,13,17]. In this study, we also observed serum Lipocalin-2 elevation in both type 2 diabetes and impaired glucose regulation. We speculate that lipocalin-2 might be involved in the regulation of glucose metabolism. This hypothesis is supported by several lines of evidence. First, lipocalin-2 knockout mice show significantly decreased fasting glucose and insulin levels and improved insulin sensitivity compared with their wild-type littermates [12]. Second, Yan et al. demonstrated that lipocalin-2 could partially block the suppressive effects of insulin on glucose production and glucose 6-phosphatase expression in hepatocytes. Finally, cells with reduction of lipocalin-2 showed elevated glucose uptake [10].

Pancreatic $\beta$-cell dysfunction and insulin resistance are hallmarks of type 2 diabetes. We found that fasting serum insulin and HOMA-IR were clearly associated with lipocalin-2 even in stepwise regression analysis, suggesting that this protein might be an indicator for $\beta$ cell function and insulin resistance in humans. Lipocalin-2 has been proposed to be an iron delivery protein [18]. Lipocalin-2 delivers iron to the cytoplasm. Iron-loaded lipocalin-2 increases intracellular iron. Iron excess might result in $\beta$ cell oxidative stress and impaired insulin secretary capacity [19]. Iron deficiency has been related to improved insulin sensitivity in animal models $[20,21]$. Epidemiologic studies also have confirmed the association between iron overload and peripheral insulin resistance [22]. Furthermore, lipocalin-2 delivers iron to the cytoplasm where it activates ferritin, an iron-responsive gene [18]. Recent study has demonstrated that elevated 
Table 1 Characteristics of the study population

\begin{tabular}{|c|c|c|c|c|c|c|c|}
\hline Characteristics & NGR (1) & IGR & & & & $P$ value & Homogeneity of groups \\
\hline & & Isolated IFG (2) & Isolated IGT (3) & IFG+IGT (4) & Type 2 diabetes (5) & & \\
\hline$n$ & 1143 & 335 & 353 & 296 & 392 & - & - \\
\hline Male, n (\%) & $502(43.9)$ & $121(36.1)$ & $164(46.5)$ & $116(39.2)$ & $173(44.1)$ & 0.55 & - \\
\hline Age (years) & $57.3 \pm 75.69$ & $58.2 \pm 7.0$ & $60.8 \pm 8.4$ & $60.2 \pm 8.5$ & $60.9 \pm 8.3$ & $<0.001$ & $(1,2)(3,4)(3,5)$ \\
\hline Current smoking, n (\%) & $211(18.5)$ & $92(27.5)$ & $79(22.4)$ & $58(19.6)$ & $117(29.8)$ & 0.25 & - \\
\hline Alcohol drinking, n (\%) & $135(11.8)$ & $41(12.2)$ & $46(13.0)$ & $29(9.8)$ & $57(14.5)$ & 0.89 & - \\
\hline BMI (kg/m2) & $24.2 \pm 3.3$ & $24.7 \pm 3.4$ & $25.1 \pm 3.2$ & $25.4 \pm 3.5$ & $25.8 \pm 3.5$ & $<0.001$ & (1) $(2)(3,4)(4,5)$ \\
\hline Waist circumference $(\mathrm{cm})$ & $81.3 \pm 8.5$ & $83.3 \pm 9.7$ & $85.1 \pm 8.5$ & $85.9 \pm 9.9$ & $87.3 \pm 9.0$ & $<0.001$ & (1) $(2,3,4)(4,5)$ \\
\hline Waist/hip ratio & $0.85 \pm 0.06$ & $0.87 \pm 0.07$ & $0.88 \pm 0.07$ & $0.89 \pm 0.10$ & $0.89 \pm 0.06$ & $<0.001$ & (1) $(2,3,4)(4,5)$ \\
\hline Fasting plasma glucose (mmol/l) & $5.3 \pm 0.5$ & $6.2 \pm 0.3$ & $5.5 \pm 0.4$ & $6.0 \pm 0.4$ & $7.4 \pm 2.4$ & $<0.001$ & (1) $(2,4)(3)(5)$ \\
\hline $2 \mathrm{~h}$ OGTT plasma glucose $(\mathrm{mmol} / \mathrm{l})$ & $5.9 \pm 0.9$ & $6.1 \pm 0.9$ & $9.1 \pm 0.9$ & $9.2 \pm 1.0$ & $14.6 \pm 4.1$ & $<0.001$ & $(1,2)(3,4)(5)$ \\
\hline Fasting serum insulin $(\mu \mathrm{U} / \mathrm{ml})$ & $6.86(4.83-9.94)$ & $\begin{array}{c}6.58 \\
(3.97-9.69)\end{array}$ & $\begin{array}{c}6.65 \\
(4.47-9.77)\end{array}$ & $6.54(4.38-9.62)$ & $\begin{array}{c}7.68 \\
(4.92-11.68)\end{array}$ & $<0.001$ & (1) $(2,3,4)(4,5)$ \\
\hline HOMA-IR & $1.56(1.06-2.39)$ & $\begin{array}{c}1.41 \\
(0.65-2.22)\end{array}$ & $\begin{array}{c}1.54 \\
(0.95-2.31)\end{array}$ & $1.39(0.74-2.33)$ & $\begin{array}{c}1.93 \\
(1.00-3.32)\end{array}$ & $<0.001$ & (1) $(2,3)(4,5)$ \\
\hline Systolic blood pressure (mmHg) & $126 \pm 17$ & $130 \pm 17$ & $132 \pm 17$ & $135 \pm 18$ & $137 \pm 18$ & $<0.001$ & (1) $(2,3,4)(4,5)$ \\
\hline Diastolic blood pressure (mmHg) & $79 \pm 9$ & $81 \pm 10$ & $82 \pm 11$ & $83 \pm 10$ & $83 \pm 10$ & $<0.001$ & (1) $(2,3,4,5)$ \\
\hline Triglycerides (mmol/l) & $1.26(0.90-1.81)$ & $1.40(0.92-1.95)$ & $\begin{array}{c}1.45 \\
(0.96-2.13)\end{array}$ & $1.35(0.95-2.12)$ & $\begin{array}{c}1.57 \\
(1.10-2.28)\end{array}$ & $<0.001$ & (1) $(2,3,4)(5)$ \\
\hline Total cholerterol (mmol/l) & $5.38 \pm 1.04$ & $5.32 \pm 0.93$ & $5.54 \pm 1.07$ & $5.34 \pm 1.07$ & $5.59 \pm 1.06$ & 0.03 & $(1,2,3,4)(5)$ \\
\hline LDL cholesterol (mmol/l) & $3.13 \pm 0.78$ & $3.11 \pm 0.69$ & $3.22 \pm 0.90$ & $3.18 \pm 0.91$ & $3.29 \pm 0.87$ & 0.21 & $(1,2,3,4)(5)$ \\
\hline HDL cholesterol (mmol/l) & $1.45 \pm 0.51$ & $1.41 \pm 0.32$ & $1.35 \pm 0.33$ & $1.28 \pm 0.31$ & $1.30 \pm 0.62$ & $<0.001$ & $(1,2)(3,4,5)$ \\
\hline CRP $(\mu \mathrm{g} / \mathrm{ml})$ & $2.41(1.11-4.95)$ & $2.35(1.18-4.99)$ & $3.58(1.61-6.56)$ & $2.73(1.37-5.48)$ & $3.53(1.62-7.22)$ & $<0.001$ & (1) $(2)(3,4,5)$ \\
\hline CXCL5 (pg/ml) & $1.7 \pm 1.3$ & $1.8 \pm 1.3$ & $1.9 \pm 1.4$ & $1.8 \pm 1.2$ & $1.9 \pm 1.9$ & 0.03 & (1) $(2,3,4,5)$ \\
\hline Adiponectin $(\mu \mathrm{g} / \mathrm{ml})$ & $10.42(7.19-14.62)$ & $9.93(6.58-13.88)$ & $9.47(6.71-13.62)$ & $10.11(7.08-13.84)$ & $9.04(6.12-12.55)$ & $<0.001$ & (1) $(2,3,4,5)$ \\
\hline Lipocalin-2 (ng/ml) & $69.2 \pm 7.8$ & $83.5 \pm 8.9$ & $92.4 \pm 10.7$ & $83.1 \pm 8.6$ & $89.2 \pm 8.3$ & $<0.001$ & (1) $(2,3,4,5)$ \\
\hline
\end{tabular}

Data are means $\pm S D, n(\%)$, or median (interquartile range) 
Table 2 Univariate and stepwise regression analysis with serum lipocalin-2 concentration as a dependent variable

\begin{tabular}{|c|c|c|c|c|c|}
\hline \multirow[t]{2}{*}{ Co-variable } & \multicolumn{3}{|l|}{ Univariate } & \multicolumn{2}{|c|}{ tepwise } \\
\hline & $r$ & $\beta(\mathrm{SEM})$ & $p$ value & $\beta($ SEM) & $p$ value \\
\hline Age (years) & 0.000 & $-0.002(0.001)$ & 0.497 & - & - \\
\hline Sex $($ male $=1$, female $=2)$ & 0.086 & $0.033(0.020)$ & 0.001 & - & - \\
\hline Body mass index (kg/m2) & 0.058 & $0.015(0.004)$ & 0.018 & $0.160(0.004)$ & $<0.001$ \\
\hline Waist circumference (cm) & 0.118 & $0.000(0.007)$ & $<0.001$ & $0.105(0.001)$ & 0.012 \\
\hline Waist/hip ratio & 0.081 & $0.151(0.580)$ & 0.005 & - & - \\
\hline Fasting plasma glucose $(\mathrm{mmol} / \mathrm{l})$ & 0.107 & $0.011(0.009)$ & $<0.001$ & - & - \\
\hline 2h OGTT plasma glucose (mmol/l) & 0.066 & $0.005(0.003)$ & 0.009 & - & - \\
\hline Log10 fasting serum insulin $(\mu \mathrm{U} / \mathrm{ml})$ & 0.263 & $0.140(0.050)$ & $<0.001$ & $0.105(0.045)$ & 0.007 \\
\hline Log10 HOMA-IR & 0.291 & $0.123(0.031)$ & $<0.001$ & $0.209(0.025)$ & $<0.001$ \\
\hline Log10 triacylglycerol (mmol/l) & 0.134 & $0.054(0.053)$ & $<0.001$ & - & - \\
\hline Total cholesterol (mmol/l) & -0.087 & $0.031(0.019)$ & $<0.001$ & $-0.075(0.008)$ & 0.006 \\
\hline $\mathrm{HDL}$ - cholesterol (mmol/l) & -0.181 & $-0.041(0.037)$ & $<0.001$ & $-0.092(0.026)$ & 0.002 \\
\hline LDL- cholesterol (mmol/l) & -0.059 & $0.009(0.020)$ & 0.016 & - & - \\
\hline Systolic blood pressure (mmHg) & 0.081 & $0.001(0.001)$ & 0.002 & - & - \\
\hline Diastolic blood pressure (mmHg) & 0.101 & $0.000(0.001)$ & $<0.001$ & - & - \\
\hline CRP $(\mu \mathrm{g} / \mathrm{ml})$ & 0.131 & $0.021(0.021)$ & $<0.001$ & - & - \\
\hline CXCL5 (pg/ml) & 0.076 & $0.084(0.026)$ & 0.003 & $0.08(0.025)$ & 0.002 \\
\hline Adiponectin $(\mu \mathrm{g} / \mathrm{ml})$ & -0.095 & $0.015(0.035)$ & $<0.001$ & - & - \\
\hline
\end{tabular}

$\beta$, Regression coefficient; $r$, Pearson correlation coefficient; SEM standard error of mean

circulating ferritin concentrations are associated with high risk for type 2 diabetes and metabolic syndrome [23]. Thus, we postulate that Lipocalin-2 might influence $\beta$ cell function and insulin sensitivity partially through mediation of iron.

Increasing evidences suggest a critical role for PPAR $\gamma$ in the regulation of insulin sensitivity. However, the exact role of lipocalin- 2 in obesity-induced insulin resistance remains controversial. Jin et al. observed developed insulin resistance and decreased adipose PPAR $\gamma$ expression in the absence of lipoclain-2 mice, suggesting that lipocalin-2 is a critical selective modulator of PPAR yactivation [24]. Jun et al. observed no difference in insulin sensitivity in lipocalin-2 knock out

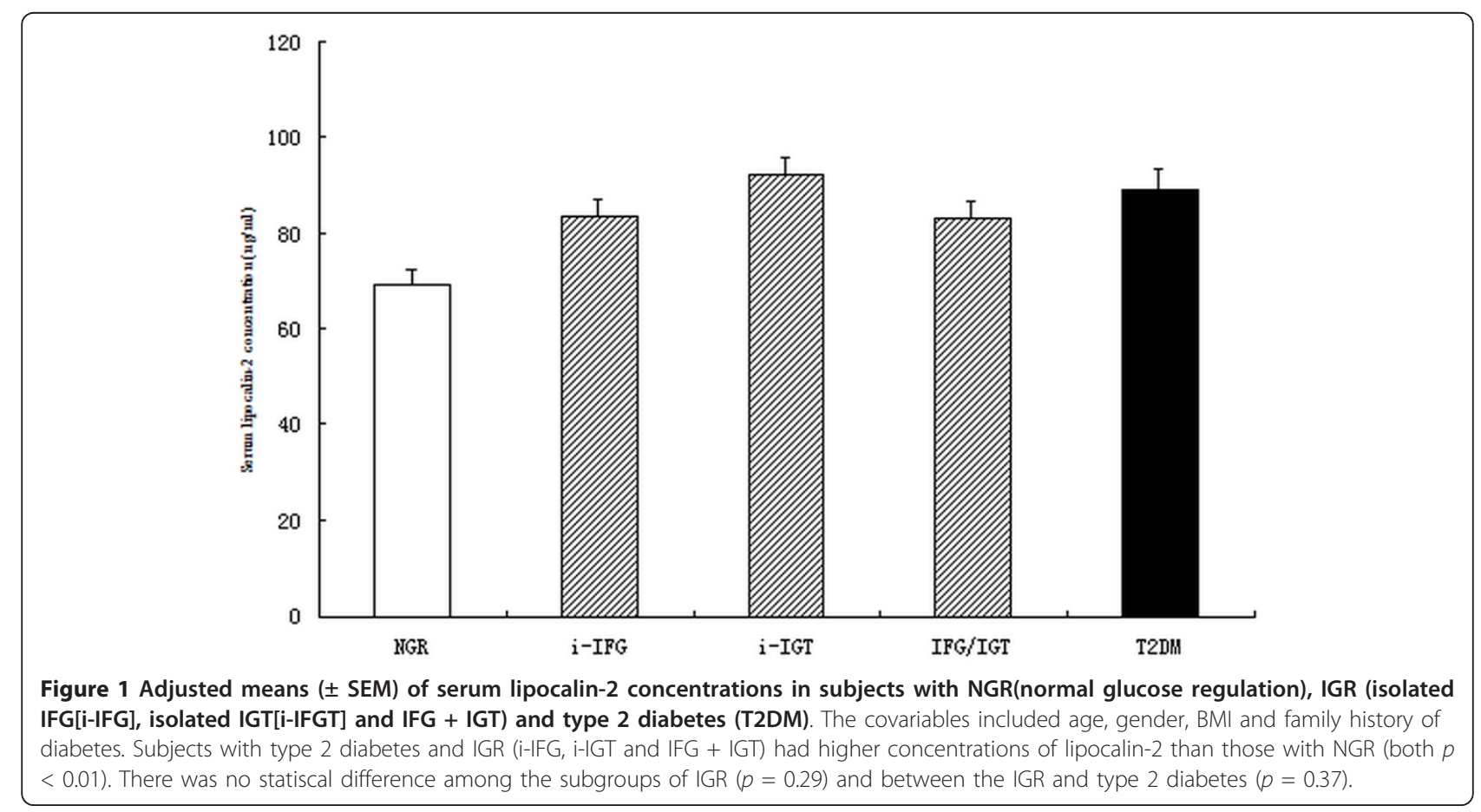


Table 3 The risk of impaired glucose regulation and type 2 diabetes associated with a $10 \mathrm{ng} / \mathrm{ml}$ increase in serum lipocalin-2

\begin{tabular}{|c|c|c|c|c|}
\hline Model & IGR $(n=984)$ & $p$ value $^{a}$ & impaired glucose regulation and type 2 diabetes $(n=1376)$ & $p$ value $^{\mathrm{b}}$ \\
\hline Model 1 & $1.48(1.34-1.87)$ & $<0.001$ & $1.55(1.43-1.97)$ & $<0.001$ \\
\hline Model 2 & $1.43(1.31-1.75)$ & $<0.001$ & $1.47(1.38-1.85)$ & $<0.001$ \\
\hline Model 3 & $1.40(1.31-1.81)$ & $<0.001$ & $1.41(1.29-1.81)$ & $<0.001$ \\
\hline Model 4 & $1.351 .24-1.65)$ & $<0.001$ & $1.38(1.25-1.81)$ & $<0.001$ \\
\hline Model 5 & $1.30(1.23-1.62)$ & 0.009 & $1.31(1.21-1.69)$ & $<0.001$ \\
\hline
\end{tabular}

Values are ORs $(95 \% \mathrm{Cl})$

Model 1: Unadjusted. Model 2: Adjusted for age, sex, smoking (yes/no), alcohol drinking (yes/no), family history of diabetes (yes/no). Model 3: Further adjusted for HOMA-IR, BMI, waist/hip ratio and adiponectin. Model 4: Further adjusted for serum triacylglycerol, total cholesterol, HDL- and LDL-cholesterol. Model 5: Further adjusted for inflammatory factors (CRP and CXCL5). ${ }^{\text {a }}$ For the risk of IGR, we defined subjects with normal glucose regulation as 0 ( $\mathrm{n}=1143$ ) and IGR as 1 $(n=984)$, excluding type 2 diabetes $(n=392)$ from the analysis. ${ }^{b}$ For the risk of combined IGR and type 2 diabetes, we defined subjects with normal glucose regulation as $0(n=1143)$ and combined IGR and type 2 diabetes as $1(n=1376)$.

mice on high-fat-diet [25]. However, our study demonstrated that serum concentrations of lipocalin-2 in humans were associated with insulin sensitivity as measured by the HOMA-IR. Consistent with our study, other study have also demonstrated that treatment with the peroxisome proliferator-activated receptor agonist rosiglitazone markedly decreased lipocalin-2 expression in mice and circulating concentrations in both mice and human [11]. Thus, further prospective large populationbased studies are needed to investigate the role of lipocalin-2 in obesity-induced insulin resistance.

Visceral fat accumulation has been well-associated with adipose tissue inflammation and insulin resistance [26]. In present study, we found that waist circumference, rather than waist/hip, is one of the independent determinants of serum lipocalin-2 levels. It has been well-documented that waist circumference reflects the amount of visceral adipose tissue, which is closely correlated with the development of metabolic disorders. Hence, the accumulated visceral fat might account for the serum lipocalin-2 elevation during insulin resistance. In line with our hypothesis, some studies have demonstrated that lipocalin-2 is selectively expressed in mouse epididymal fat depot and its expression is highly induced during adipocyte differentiation $[27,28]$. Moreover, the expression of lipocalin-2 in visceral adipose tissue was found to be correlated with its circulating levels in animal models [13]. Certainly, more work is urgently needed to clarify whether visceral adipose tissue plays a causal role in the elevation of lipocalin-2.

Type 2 diabetes was associated with wide pathophysiological pathways, including inflammation [29]. CRP is a pattern-recognition molecule of innate immunity as an acutephase reactant and a hallmark of low-grade systemic inflammation. We confirmed the strong and positive association between lipocalin-2 and CRP levels observed in previous studies [11], suggesting elevated serum lipocalin2 in prediabetes and type 2 diabetes might associate with chronic inflammation. Previous studies have demonstrated that circulating CRP is an independent risk factor for type
2 diabetes and atherosclerosis [30,31]. Yan et al. found that IL-1 $\beta$ and TNF $\alpha$ are both strong inducers of lipocalin-2 production [10]. Another study shows that lipocalin2 directly stimulates the expression and activity of 12-lipoxygenase as well as TNF- $\alpha$ production in fat tissue. Conversely, these changes were attenuated in lipocalin-2 deficient mice [12]. These findings suggested that lipocalin-2 might play a causal role in the pathogenesis of inflammation. However, lipocalin-2 has recently been claimed to exert antiinflammatory function, and these effects were associated with its modulation of PPAR $\gamma$ activity via direct or indirect mechanisms by inhibiting NFkB activity [27]. In our study we found that CRP is not an independent risk of lipocalin-2. With the cross-sectional nature, we are limited in the ability to evaluate whether elevated lipocalin-2 is a protective mechanism against overactivaion of inflammation or an inflammation inducer.

One of the interesting findings of the present study is that the concentration of lipocalin-2 is also associated with CXC ligand 5 (CXCL5). Elevated CXCL5 levels were strongly and independently associated with insulin resistance [32]. CXCL5 is an adipose tissue derived factor that links obesity with insulin resistance. CXCL5 blocks insulin signaling by activating the Jak2/STAT5/ SOCS2 pathway. CXCL5 levels were also demonstrated to have a positive association with inflammatory factor CRP in our previous study [14]. Taken together, lipocalin-2 and CXCL5, as innate immunity indicators, are both serum markers of low-grade systemic inflammatory response and could potentially modulate chronic inflammatory processes.

To our knowledge, this is the first study to investigate the association of serum lipocalin-2 and the development of type 2 diabetes as well as impaired glucose regulation in Chinese. The main strength of our study is that all diabetic participants were newly diagnosed. None had used glucose-lowering treatment or insulin. Hence, the confounding effect of glucose-lowering treatment could be excluded. Anyway, there are still some 
limitations in this work. First, HbA1c levels were not measured in this study, some patients with diabetes might have been missed. Second, No causal relationship between lipocalin-2 levels and the risk of impaired glucose regulation or diabetes can be drawn, since the study was cross-sectional designed.

\section{Conclusion}

In conclusion, our study indicates that serum lipocalin-2 is independently correlated with impaired glucose regulation and type 2 diabetes. Although the underlying pathophysiological mechanisms remain unclear, it seems that insulin resistance and chronic low-grade systematic inflammation may be involved in this association.

\section{Acknowledgements}

This work was supported by the National Natural Science Foundation of China (81000344, 81070238, 81030014, 30900541, 30900502), Shanghai Education Committee Foundation (11ZZ33), Shanghai Pujiang Foundation (PJ1408400), Shanghai Science and Technology Commission (08dj1400605, 08JC1403200, 09DZ1950200), the National High Technology Research and Development Program ("863" Program) of China (2009AA022704), China Postdoctoral Science Foundation (20080440078), and Shanghai Postdoctoral Scientific Program (09R21411600).

\section{Author details \\ 'Institute of Endocrinology and Diabetology, Huashan hospital, Shanghai Medical College, Fudan University, Shanghai, China. ${ }^{2}$ Department of Endocrinology, Shanghai tenth people's hospital, School of medicine, Tongji University, Shanghai, China. ${ }^{3}$ Department of Endocrinology, Xinhua hospital, School of medicine, Shanghai Jiaotong University, Shanghai, China.}

\section{Authors' contributions}

Conceived and designed the experiments: $Z Y, R H$ Performed the experiments: YH, ZY, QL Analyzed the data: ZY Contributed reagents/ materials/analysis tools: JW, XT, LC, MH, XW, BL, ZZ, WZ, SQ. Wrote the paper: YH All authors read and approved the final manuscript.

\section{Competing interests}

The authors declare that they have no competing interests.

Received: 7 November 2011 Accepted: 31 January 2012 Published: 31 January 2012

\section{References}

1. Gelsinger C, Tschoner A, Kaser S, Ebenbichler CF: Adipokine update - new molecules, new functions. Wien Med Wochenschr 2010, 160(15-16):377-390.

2. Rasouli N, Kern PA: Adipocytokines and the metabolic complications of obesity. J Clin Endocrinol Metab 2008, 93(11 Suppl 1):S64-S73.

3. Fernandez-Real JM, Ricart W: Insulin resistance and chronic cardiovascular inflammatory syndrome. Endocr Rev 2003, 24(3):278-301.

4. Kjeldsen $L$, Johnsen $A H$, Sengelov $H$, Borregaard $N$ : Isolation and primary structure of NGAL, a novel protein associated with human neutrophil gelatinase. J Biol Chem 1993, 268(14):10425-10432.

5. Kjeldsen L, Bainton DF, Sengelov H, Borregaard N: Identification of neutrophil gelatinase-associated lipocalin as a novel matrix protein of specific granules in human neutrophils. Blood 1994, 83(3):799-807.

6. Flower DR: The up-and-down beta-barrel proteins: three of a kind. FASEB J 1995, 9(7):566-567.

7. Devireddy LR, Teodoro JG, Richard FA, Green MR: Induction of apoptosis by a secreted lipocalin that is transcriptionally regulated by IL-3 deprivation. Science 2001, 293(5531):829-834.

8. Stoesz SP, Gould MN: Overexpression of neu-related lipocalin (NRL) in neu-initiated but not ras or chemically initiated rat mammary carcinomas. Oncogene 1995, 11(11):2233-2241.
9. Flo TH, Smith KD, Sato S, Rodriguez DJ, Holmes MA, Strong RK, Akira S, Aderem A: Lipocalin 2 mediates an innate immune response to bacterial infection by sequestrating iron. Nature 2004, 432(7019):917-921.

10. Yan QW, Yang Q, Mody N, Graham TE, Hsu CH, Xu Z, Houstis NE, Kahn BB, Rosen ED: The adipokine lipocalin 2 is regulated by obesity and promotes insulin resistance. Diabetes 2007, 56(10):2533-2540.

11. Wang Y, Lam KS, Kraegen EW, Sweeney G, Zhang J, Tso AW, Chow WS, Wat NM, Xu JY, Hoo RL, et al: Lipocalin-2 is an inflammatory marker closely associated with obesity, insulin resistance, and hyperglycemia in humans. Clin Chem 2007, 53(1):34-41.

12. Law IK, Xu A, Lam KS, Berger T, Mak TW, Vanhoutte PM, Liu JT, Sweeney G, Zhou M, Yang B, et al: Lipocalin-2 deficiency attenuates insulin resistance associated with aging and obesity. Diabetes 2010, 59(4):872-882.

13. Auguet $T$, Quintero $Y$, Terra $X$, Martinez $S$, Lucas A, Pellitero $S$, Aguilar $C$, Hernandez M, Del CD, Richart C: Upregulation of Lipocalin 2 in Adipose Tissues of Severely Obese Women: Positive Relationship With Proinflammatory Cytokines. Obesity (Silver Spring) 2011, 19(12):2295-300.

14. Yang Z, Zhang Z, Wen J, Wang X, Lu B, Yang Z, Zhang W, Wang M, Feng X, Ling C, et al: Elevated serum chemokine CXC ligand 5 levels are associated with hypercholesterolemia but not a worsening of insulin resistance in Chinese people. J Clin Endocrinol Metab 2010, 95(8):3926-3932.

15. Zhou BF: Predictive values of body mass index and waist circumference for risk factors of certain related diseases in Chinese adults-study on optimal cut-off points of body mass index and waist circumference in Chinese adults. Biomed Environ Sci 2002, 15(1):83-96.

16. American Diabetes Association: Diagnosis and classification of diabetes mellitus. Diabetes Care 2005, 28:S37-S42.

17. Cakal E, Ozkaya M, Engin-Ustun Y, Ustun Y: Serum lipocalin-2 as an insulin resistance marker in patients with polycystic ovary syndrome. J Endocrinol Invest 2011, 34(2):97-100.

18. Yang J, Goetz D, Li JY, Wang W, Mori K, Setlik D, Du T, ErdjumentBromage $H$, Tempst $P$, Strong $R$, et al: An iron delivery pathway mediated by a lipocalin. Mol Cell 2002, 10(5):1045-1056.

19. Cooksey RC, Jouihan HA, Ajioka RS, Hazel MW, Jones DL, Kushner JP, McClain DA: Oxidative stress, beta-cell apoptosis, and decreased insulin secretory capacity in mouse models of hemochromatosis. Endocrinology 2004, 145(11):5305-5312.

20. Borel MJ, Beard JL, Farrell PA: Hepatic glucose production and insulin sensitivity and responsiveness in iron-deficient anemic rats. Am J Physiol 1993, 264(3 Pt 1):E380-E390.

21. Farrell PA, Beard JL, Druckenmiller M: Increased insulin sensitivity in irondeficient rats. J Nutr 1988, 118(9):1104-1109.

22. Dandona P, Hussain MA, Varghese Z, Politis D, Flynn DM, Hoffbrand AV: Insulin resistance and iron overload. Ann Clin Biochem 1983, 20(Pt 2):77-79.

23. Sun L, Franco OH, Hu FB, Cai L, Yu Z, Li H, Ye X, Qi Q, Wang J, Pan A, et al: Ferritin concentrations, metabolic syndrome, and type 2 diabetes in middle-aged and elderly chinese. J Clin Endocrinol Metab 2008, 93(12):4690-4696.

24. Jin D, Guo H, Bu SY, Zhang Y, Hannaford J, Mashek DG, Chen X: Lipocalin 2 is a selective modulator of peroxisome proliferator-activated receptorgamma activation and function in lipid homeostasis and energy expenditure. FASEB J 2011, 25(2):754-764.

25. Jun LS, Siddall CP, Rosen ED: A minor role for lipocalin 2 in high-fat dietinduced glucose intolerance. Am J Physiol Endocrinol Metab 2011, 301(5): E825-E835.

26. Alvehus M, Buren J, Sjostrom M, Goedecke J, Olsson T: The human visceral fat depot has a unique inflammatory profile. Obesity (Silver Spring) 2010, 18(5):879-883.

27. Zhang J, Wu Y, Zhang Y, Leroith D, Bernlohr DA, Chen X: The role of lipocalin 2 in the regulation of inflammation in adipocytes and macrophages. Mol Endocrinol 2008, 22(6):1416-1426.

28. Kratchmarova I, Kalume DE, Blagoev B, Scherer PE, Podtelejnikov AV, Molina H, Bickel PE, Andersen JS, Fernandez MM, Bunkenborg J, et al: A proteomic approach for identification of secreted proteins during the differentiation of 3 T3-L1 preadipocytes to adipocytes. Mol Cell Proteomics 2002, 1(3):213-222.

29. Teixeira-Lemos E, Nunes S, Teixeira F, Reis F: Regular physical exercise training assists in preventing type 2 diabetes development: focus on its 
antioxidant and anti-inflammatory properties. Cardiovasc Diabetol 2011,

10:12.

30. Haffner SM: The metabolic syndrome: inflammation, diabetes mellitus, and cardiovascular disease. Am J Cardiol 2006, 97(2A):3A-11A.

31. Tsimikas S, Willerson JT, Ridker PM: C-reactive protein and other emerging blood biomarkers to optimize risk stratification of vulnerable patients. $J$ Am Coll Cardiol 2006, 47(8 Suppl):C19-C31.

32. Chavey C, Lazennec G, Lagarrigue S, Clape C, lankova I, Teyssier J, Annicotte JS, Schmidt J, Mataki C, Yamamoto H, et al: CXC ligand 5 is an adipose-tissue derived factor that links obesity to insulin resistance. Cell Metab 2009, 9(4):339-349.

doi:10.1186/1475-2840-11-11

Cite this article as: Huang et al: Lipocalin-2, glucose metabolism and

chronic low-grade systemic inflammation in Chinese people.

Cardiovascular Diabetology 2012 11:11.

\section{Submit your next manuscript to BioMed Central} and take full advantage of:

- Convenient online submission

- Thorough peer review

- No space constraints or color figure charges

- Immediate publication on acceptance

- Inclusion in PubMed, CAS, Scopus and Google Scholar

- Research which is freely available for redistribution

Submit your manuscript at www.biomedcentral.com/submit 